\title{
SUSTAINABLE SUPPLY CHAIN: A MODIFICATION SUGGESTION TO AN EXISTING STRATEGIC FRAMEWORK
}

\author{
Birsen Karpak \\ Youngstown State University, \\ Youngstown, $\mathrm{OH} 44555$ \\ bkarpak@ysu.edu
}

\begin{abstract}
Supply chain management is a prosperous area of research for AHP/ANP scientists. There have already been quite a few AHP/ANP applications. This presentation suggests an improvement in one of the existing ANP based strategic decision frameworks published in the literature.

The published strategic framework for green supply chain management considers product life cycle (PLC) influence, the impact of operational life Cycle (OLC), organizational performance requirements' (OPR) and environmentally influential organizational practices - which constitutes the clusters of ANP upon green supply chain alternatives.

In this study the framework has been augmented with the social dimension of sustainability. Therefore the proposed strategic model is a model for sustainable supply chain management. In addition, it is illustrated that both the framework in literature and the one proposed by the author are valid for focal companies. Supply chains which leadership executed by a "steering committee," requires group decision making models. This is another area of research. Applicability of ANP is illustrated to evaluate sustainable supply chain alternatives. The author would like to get feedback from the audience in her early stage of research.
\end{abstract}

Keywords: Sustainable Supply Chain Management, ANP model

\section{Introduction}

Globalization and outsourcing have increased the complexity of supply chains. Sustainable Supply chain management is the management of material and informational flows as well as cooperation among companies along the supply chain while taking goals from all three dimensions of sustainable development, economic, environmental and social requirements into account. Future generations should not be negatively impacted by decisions today.

It is common practice for decision makers to address the economic pillar of sustainability (Hutchins and Sutherland, 2008), and over the last decade, increasing effort has been directed at the environmental pillar through attention to environmental life cycle impacts. Research is still dominated by green/environmental issues. Social aspects and also integration of the three dimensions of sustainability are still rare. The strategic model developed by Sarkis (2008) misses the social dimension of sustainability. In this study we are augmenting the framework to include social factors.

In practice, supply chain leadership maybe executed either by a focal company or a steering committee (Hartmut and Stadter, 2008). A focal company usually a member having the largest (financial) power, the 
best know-how of products and processes or has the greatest of values created during order fulfillment. For these reasons decisions made by the focal company will be accepted by all members. On the other hand a steering committee may be introduced consisting of representatives of all members of supply chain. In this case, group decision making rules apply. Though it has not been mentioned, we contend that the framework proposed by Sarkis (2008) is valid for supply chains which the leadership is executed by focal companies.

Recently researchers have begun to realize that the decision and integration effort in supply chain design should be driven by the manufactured product (Wang, et al. 2004). Supply chains are classified as lean, agile, and hybrid based on the product type and product life cycle and it is contended that the strategic supply chain alternatives should be evaluated based on the type of the supply chain under consideration. In this presentation the framework has been augmented considering lean chain. It is demonstrated that organizational performance requirements will differ depending on the supply chain considered. Another suggested augmentation is including the social performance into the strategic framework; therefore, a new recommended strategic framework integrates all three dimensions of sustainability.

\section{ANP based framework}

Sarkis (2008) presents an ANP based strategic framework for green supply chain management. The model considers product life cycle (PLC) influence, the operational life cycle (OLC) impact, organizational performance requirements (PER) and environmentally influential organizational practices (ENV) upon green supply alternatives. We have augmented the framework with social performance of the suppliers cluster which consists of labor equity, healthcare, safety and philanthropy indicators proposed by Hutchins and Sutherland (2008). Sarkis considers the environmentally influential practices of the focal company (ENVF). We contend that environmentally influential practices of the partners (ENVP) should also be included in the framework. Proposed framework is given in Figure 1.

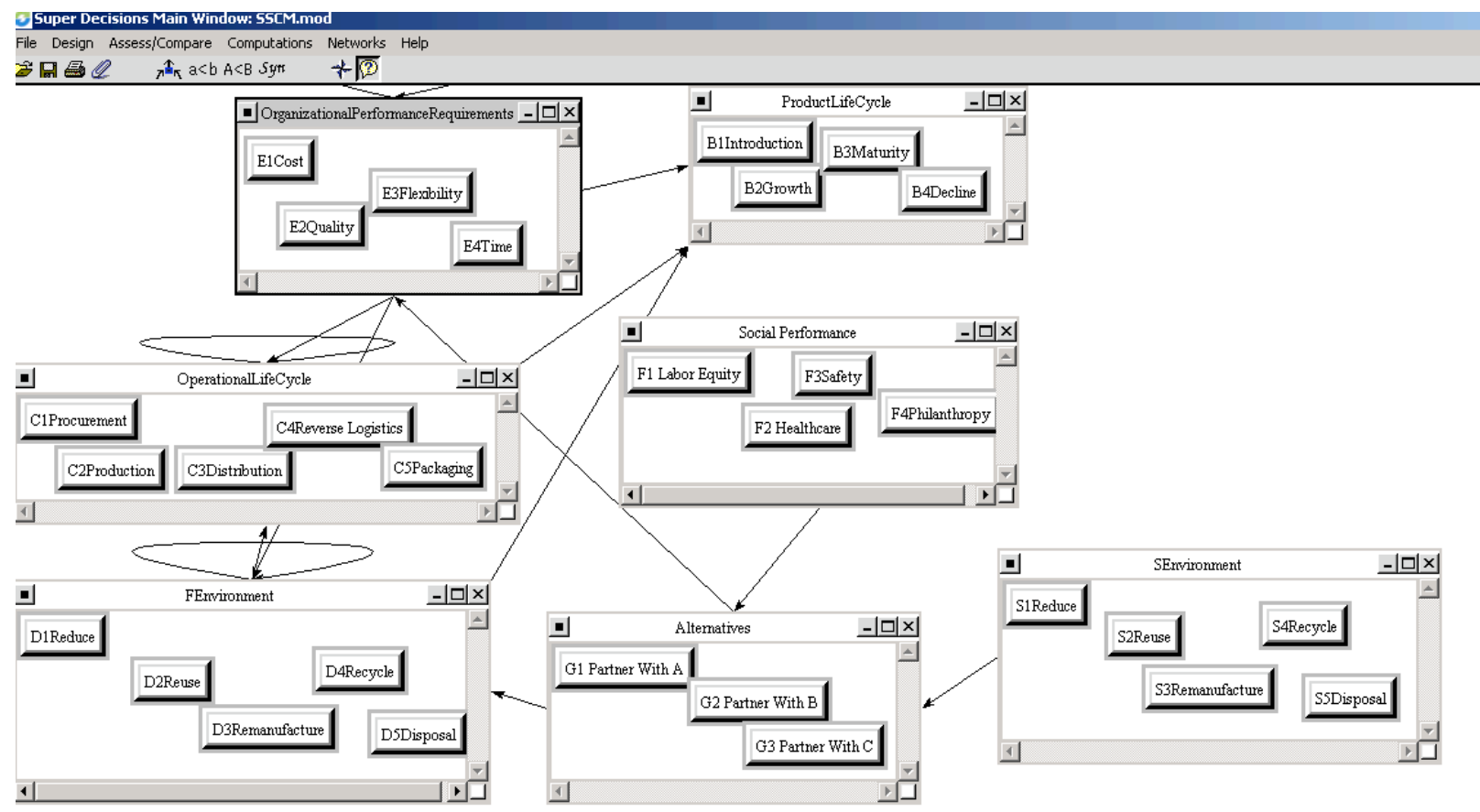

Figure 1. Strategic Framework for Sustainable Supply Chain Management.

Overall objective of the framework is to identify the partners which contribute most to the sustainable supply chain. Model evaluates the partners for the entire Product life cycle (PLC). There are outer 
dependencies between PLC and operational life cycle (OLC) and environmentally influential organizational practices of the focal company (ENVF). For example in the introduction phase of PLC, procurement is more influential than production for sustainable supply chain management (SSCM). On the other hand in maturity and decline stage of PLC efficient reverse logistic is more influential than distribution operations for SSCM. There are inner dependencies among procurement, production, distribution and reverse logistics of OLC. Distribution outlet locations, mode of transportation to be used, control systems, and just in time policies, will not only influence the forward logistics network, but also the reverse logistics network. The definition of reverse logistics from an environmental perspective focuses primarily on the return of recyclable or reusable products and materials into the forward supply chain. Reverse logistics, flow of materials from the customer to forward supply chain, is the least studied operational function (Sarkis, 2008).

The components of the clusters proposed by Sarkis (2008) are briefly explained. Environmentally influential organizational practices of the suppliers cluster (ENVS) has the same components as the focal company's ENVF. The only difference is that reduce, reuse, remanufacture, recycle, disposal practices of the supplier upon sustainable supply change management are evaluated. When comparing two strategic partners whichever is more influential in terms of certain practices is more promising than the other. Degree of influence has been measured with regular scale of AHP/ANP, 1, 3, 5, 7, and 9 (Saaty, 2005). Verbal mode is used rather than numerical mode since verbal comparison mode dominates numerical one based on perceived ease of use and accuracy criteria (Bayazit and Karpak, 2005).

Components of the new clusters offered by this study are explained in more detail. Hutchins and Sutherland (2008) propose the following definitions for labor equity, healthcare, safety, and philanthropy components of the social performance cluster. For labor equity it is proposed to use the ratio of the average hourly labor cost (including benefits and taxes) to the total compensation package (converted to and hourly measure) for the company's highest paid employee. For healthcare it is proposed to use the ratio of company paid healthcare expenses per employee to the market capitalization per employee. A better measure might be the ratio of health maintenance expenses to the market capitalization. However, health maintenance expenses might not be publicly available, and aggregated with other expenses. For safety the ratio of average days not injured to the total days worked is selected for this indicator. For philanthropy, the ratio of charitable contributions to market capitalization is proposed.

The framework has been implemented into an illustrative lean supply chain (figure 2). Super decisions software is used (www.superdecisions.com, 2008). Partner B seems to be the best strategic partner contributing most for all three pillars of sustainability combined. Cost and quality are the most influential performance indicators. Recycle followed by remanufacture and reuse are the most significant environmentally influential organizational practices. Model recommends that decision makers should be more cautious in the introduction and the growth stage of product life cycle since these two product life cycle stages are most influential on sustainable management practices. 


\begin{tabular}{|c|c|c|c|c|}
\hline \multicolumn{3}{|c|}{ Super Decisions Main Window: 55CM.mod: Priorities } & \multicolumn{2}{|c|}{ - } \\
\hline \multicolumn{5}{|c|}{ Here are the priorities. } \\
\hline Icon & Name & $\mid$ Normalized by Cluster & $\longdiv { \overline { \text { Limiting } } }$ & $\Delta$ \\
\hline Nolcon & G1 Partner With A & 0.30323 & 0.110812 & \\
\hline Nolcon & G2 Partner With B & 0.39611 & 0.144755 & \\
\hline Nolcon & G3 Partner With $\mathrm{C}$ & 0.30067 & 0.109877 & \\
\hline Nolcon & D1Reduce & 0.28832 & 0.072298 & \\
\hline Nolcon & D2Reuse & 0.13152 & 0.032980 & \\
\hline Nolcon & D3Remanufacture & 0.14537 & 0.036452 & \\
\hline Nolcon & D4Recycle & 0.37906 & 0.095052 & \\
\hline Nolcon & D5Disposal & 0.05574 & 0.013977 & \\
\hline Nolcon & C1Procurement & 0.53391 & 0.011792 & \\
\hline Nolcon & C2Production & 0.25048 & 0.005532 & \\
\hline Nolcon & C3Distribution & 0.08675 & 0.001916 & \\
\hline Nolcon & C4Reverse Logistics & 0.04179 & 0.000923 & \\
\hline Nolcon & C5Packaging & 0.08707 & 0.001923 & \\
\hline Nolcon & E1Cost & 0.47062 & 0.136133 & \\
\hline Nolcon & E2Quality & 0.39863 & 0.115309 & \\
\hline Nolcon & E3Flexibility & 0.08713 & 0.025203 & \\
\hline Nolcon & E4Time & 0.04361 & 0.012616 & \\
\hline Nolcon & B11ntroduction & 0.29695 & 0.005061 & \\
\hline Nolcon & B2Growth & 0.53964 & 0.009197 & \\
\hline Nolcon & B3Maturity & 0.16341 & 0.002785 & \\
\hline Nolcon & B4Decline & 0.00000 & 0.000000 & \\
\hline Nolcon & S1Reduce & 0.27623 & 0.007652 & \\
\hline
\end{tabular}

Figure 2. Priorities for an illustrative lean supply chain. 


\section{Conclusion}

The issue of organizations incorporating natural and social environment into strategic and operational decisions is a reality that they will or have already encountered. The influences of the natural and social environment upon organizational decisions will not only affect the focal company but its customers and suppliers as well. Majority of the partners of big supply chains are small medium enterprises (SMEs). Tremendous opportunities exist to influence the operating practices and technologies of SMEs to incorporate environmental and social initiatives. Organizations view many of these environmental and social programs which may include technological and organizational development projects as possible options for gaining or maintaining a competitive advantage. One such decision framework that considers various elements, functions and activities of supply chain and interactions among them whose goal is to achieve sustainable supply chain is introduced. The framework prioritizes strategic partners. It can also be used to evaluate different projects, technologies, etc. The decision framework is modeled and solved with an illustrative example, as an analytic network process (ANP).

ANP has superiority over AHP since it can handle dependencies among factors. On the other hand ANP requires quite a few pairwise comparisons which could be quite time demanding from the decision makers.

A consensus has not been reached regarding the measurement of sustainability. Supporting local small businesses can be incorporated into social performance indicators which has follow on benefits in terms of well being and health of the local population. Improving the framework for service supply chains is another area of research.

Application of the framework for illustrative agile and hybrid supply chains is planned. Yet the application of the proposed model for an actual supply chain should be far more interesting. Supply chains which leadership executed by a "steering committee," is far more challenging, requires group decision making models (Saaty and Peniwati, 2008).

\section{REFERENCES}

Bayazit, O. \& Karpak, B. (2007). An analytical network process-based framework for successful total quality management (TQM): An assessment of Turkish manufacturing industry readiness. International Journal of Production Economics, 105, 79-96.

Hutchins, M.J., \& Sutherland J.W. (2008). An exploration of measures of social sustainability and their application to supply chain decisions, Journal of Cleaner Production, 16, 1688-1698.

Saaty, T.L. (2005). Theory and Applications of the Analytic Network Process: Decision Making with Benefits, Opportunities, Cost, and risks. Pittsburgh, PA: RWS Publications.

Saaty, T.L., \& Peniwati, K. (2008). Group decision-making: Drawing out and reconciling differences. Pittsburgh, PA: RWS Publications. 
Sarkis, J. (2003). A strategic decision framework for green supply chain management, Journal of Cleaner Production, 11, 397-409.

Stadler, H. (2008). Supply chain management-an overview in Supply Chain Management and Advanced Planning (Stadler, H, Kilger, C. editors) Springer-Verlag, Berlin Heidelberg

Wang, G., Huang, S.H.,\& Dismukes, J.P. (2004). Product-driven supply chain selection using integrated multi-criteria decision-making methodology. International Journal of Production Economics, 91, 1-15

Super decisions, (2008) www.superdecisions.com 